\title{
Underdiagnoses of Rickettsia in patients hospitalized with acute fever in Indonesia: observational study results
}

Dewi Lokida ${ }^{1,2+}$, Usman Hadi ${ }^{3 \dagger}$, Chuen-Yen Lau ${ }^{4}$, Herman Kosasih ${ }^{2^{*}}$ (D, C. Jason Liang ${ }^{4}$, Musofa Rusli ${ }^{3}$, Pratiwi Sudarmono ${ }^{5}$, Nurhayati Lukman², Kanti Laras ${ }^{2}$, Rizka Humardewayantie Asdie ${ }^{6}$, Dewi Murniati ${ }^{7}$, I Made Susila Utama ${ }^{8}$, Risna Halim Mubin ${ }^{9}$, Muhammad Karyana ${ }^{2,10}$, Muhammad Hussein Gasem ${ }^{11}$ and Bachti Alisjahbana ${ }^{12}$

\begin{abstract}
Background: Reports of human rickettsial infection in Indonesia are limited. This study sought to characterize the epidemiology of human rickettsioses amongst patients hospitalized with fever at 8 tertiary hospitals in Indonesia.

Methods: Acute and convalescent blood from 975 hospitalized non-dengue patients was tested for Rickettsia lgM and IgG by ELISA. Specimens from cases with seroconversion or increasing IgM and/or IgG titers were tested for Rickettsia IgM and IgG by IFA and Rickettsia genomes using primers for Rickettsia (R.) sp, R. typhi, and Orientia tsutsugamushi. Testing was performed retrospectively on stored specimens; results did not inform patient management.
\end{abstract}

Results: R. typhi, R. rickettsii, and O. tsutsugamushi lgG antibodies were identified in 269/872 (30.8\%), 36/634 (5.7\%), and 19/504 (3.8\%) of samples, respectively. For the 103/975 (10.6\%) non-dengue patients diagnosed with acute rickettsial infection, presenting symptoms included nausea (72\%), headache (69\%), vomiting (43\%), lethargy (33\%), anorexia (32\%), arthralgia (30\%), myalgia (28\%), chills (28\%), epigastric pain (28\%), and rash (17\%). No acute rickettsioses cases were suspected during hospitalization. Discharge diagnoses included typhoid fever (44), dengue fever (20), respiratory infections (7), leptospirosis (6), unknown fever (6), sepsis (5), hepatobiliary infections (3), UTI (3), and others (9). Fatalities occurred in 7 (6.8\%) patients, mostly with co-morbidities.

Conclusions: Rickettsial infections are consistently misdiagnosed, often as leptospirosis, dengue, or Salmonella typhi infection. Clinicians should include rickettsioses in their differential diagnosis of fever to guide empiric management; laboratories should support evaluation for rickettsial etiologies; and public policy should be implemented to reduce burden of disease.

Keywords: Rickettsioses, Indonesia, Clinical pathway

\footnotetext{
* Correspondence: hkosasih@ina-respond.net

${ }^{\dagger}$ Dewi Lokida and Usman Hadi are co-first authors with equal contributions. ${ }^{2}$ Indonesia Research Partnership on Infectious Disease (INA-RESPOND), Badan Litbangkes, Building 4, 5th floor, Jl Percetakan Negara no 29, Jakarta 10560, Indonesia

Full list of author information is available at the end of the article
}

(c) The Author(s). 2020 Open Access This article is licensed under a Creative Commons Attribution 4.0 International License, which permits use, sharing, adaptation, distribution and reproduction in any medium or format, as long as you give appropriate credit to the original author(s) and the source, provide a link to the Creative Commons licence, and indicate if changes were made. The images or other third party material in this article are included in the article's Creative Commons licence, unless indicated otherwise in a credit line to the material. If material is not included in the article's Creative Commons licence and your intended use is not permitted by statutory regulation or exceeds the permitted use, you will need to obtain permission directly from the copyright holder. To view a copy of this licence, visit http://creativecommons.org/licenses/by/4.0/ The Creative Commons Public Domain Dedication waiver (http://creativecommons.org/publicdomain/zero/1.0/) applies to the data made available in this article, unless otherwise stated in a credit line to the data. 


\section{Background}

Rickettsioses are arthropod-borne zoonoses caused by obligate intracellular bacteria from Rickettsia or Orientia genera. They include murine typhus, spotted fever, and scrub typhus groups [1]. Small mammals serve as reservoirs and arthropods (ticks, fleas, lice, and mites) as vectors. Humans are incidental hosts for many pathogenic rickettsiae [2].

Human rickettsioses in Indonesia are not well characterized. Limited reports have found murine typhus in travelers returning from Indonesia [3-5]. In 2004, over 450 travel-associated cases were reported worldwide; a significant proportion were $R$. typhi from tropical and subtropical areas, $R$. conorii from Southern Asia and $O$. tsutsugamushi from the Asia-Pacific $[6,7]$. An active surveillance study of children in Asia showed that $7.6 \%$ of Indonesian cases were due to Rickettsia [8]. Other fever studies revealed prevalence of murine typhus, spotted fever, and scrub typhus in Northeastern Papua to be 5,1 , and $3 \%$, respectively [9], whereas prevalence of murine typhus in Central Java was 7\% [10].

Clinically, rickettsioses are difficult to distinguish from other conditions causing acute fever in endemic areas, especially during the early phase. Common presentations include fever, abdominal discomfort, headache, myalgia, and rashes. Lung, liver, and kidney involvement may complicate the disease [7]. Given the non-specific clinical syndrome and limited access to diagnostics, rickettsioses are likely underdiagnosed in Indonesia. Underdiagnoses could engender inappropriate management, treatment delays, prolonged hospitalisation, and increased morbidity and mortality [11, 12]. Therefore, early diagnosis and empirical therapy of rickettsioses are important.

To characterize the epidemiology of rickettsioses in Indonesia, we performed Rickettsia diagnostic panels on blood from subjects in the Acute Fever Requiring Hospitalization (AFIRE) study [13]. Presentation of rickettsial infection in subjects that were initially diagnosed with another infection such as dengue, salmonella and leptospirosis were evaluated to identify features that may confound diagnosis of rickettsiosis.

\section{Methods}

\section{Study subjects and sample collection}

Patients found to have rickettsial infection by reference laboratory testing were identified from INA-RESPOND's [14] AFIRE observational cohort study conducted in Indonesia from 2013 to 2016 . It recruited patients presenting to hospital for evaluation of acute fever, at least 1 year old, hospitalized within the past $24 \mathrm{~h}$, and not hospitalized within the past 3 months. Study sites were eight tertiary hospitals in seven cities in Indonesia: Bandung, Denpasar, Jakarta, Makassar, Semarang, Surabaya and Yogyakarta. Details of AFIRE have been previously described [13].

Subjects were evaluated at enrollment, between 14 and 28 days post-enrollment and 3 months post-enrollment. Demographics, clinical data, blood and other clinically indicated specimens were collected during these visits. Blood specimens from the first visit were considered "acute" and specimens from the two follow-up visits were considered "convalescent". Buffy coat and plasma from blood were stored at $-70{ }^{\circ} \mathrm{C}$ and tested retrospectively for pathogens approximately 1 year after enrollment. Specimens from 1464 subjects were first screened for dengue infection. Non-dengue cases were then tested for other pathogens, including Rickettsia. Details of the diagnostic procedures are shown in Fig. 1.

\section{Serologic assay}

R. typhi IgM, R. rickettsii IgM, R. typhi IgG, and Spotted fever group IgG were tested using enzyme-linked immunosorbent assay (ELISA) (Fuller Laboratories, San Fransisco, CA). IgM and IgG for Scrub typhus were tested using ELISA (InBios, Seattle, WA). Detailed methods for these assays have been described previously $[15,16]$. Convalescent plasma from 975 patients were tested for IgG against $R$. typhi. Due to logistic reasons, only a subset was tested for spotted fever group ( $n=$ $634)$ and scrub typhus $(n=504)$. If IgG was positive, IgM and IgG from acute and convalescent plasma were tested simultaneously to assess seroconversion, increase or high optical density and index value in paired samples. In these subjects, indirect immunofluorescence assay (IFA) was performed to detect IgM and IgG reactivity to $R$. typhi and $R$. ricketsii (Focus diagnostics, CA) following the manufacturer's procedures as previously described [15]. A specimen was considered positive when IgM or IgG fluorescence was observed in the 1:64 dilution. To determine four-fold increase, acute specimens were diluted by two-fold until IgM or IgG fluorescence was not observed. The dilution where IgM or IgG fluorescence was still detected was the end titer of the specimens. The corresponding convalescent specimens was then diluted four-fold of the end titer dilution of the acute specimens. Four-fold increase of IgM or IgG was confirmed when fluorescence was still detected in these diluted convalescent specimens [17]. Seroconversion of IgM or IgG antibodies was confirmed when no fluorescence was detected in 1:64 dilution in acute specimens but was detected in 1:64 dilution in convalescent specimens.

\section{Molecular assay}

Acute plasma and buffy coat from subjects with seroconversion or increased IgM/IgG and from subjects that only had acute specimens were tested using PCR. 


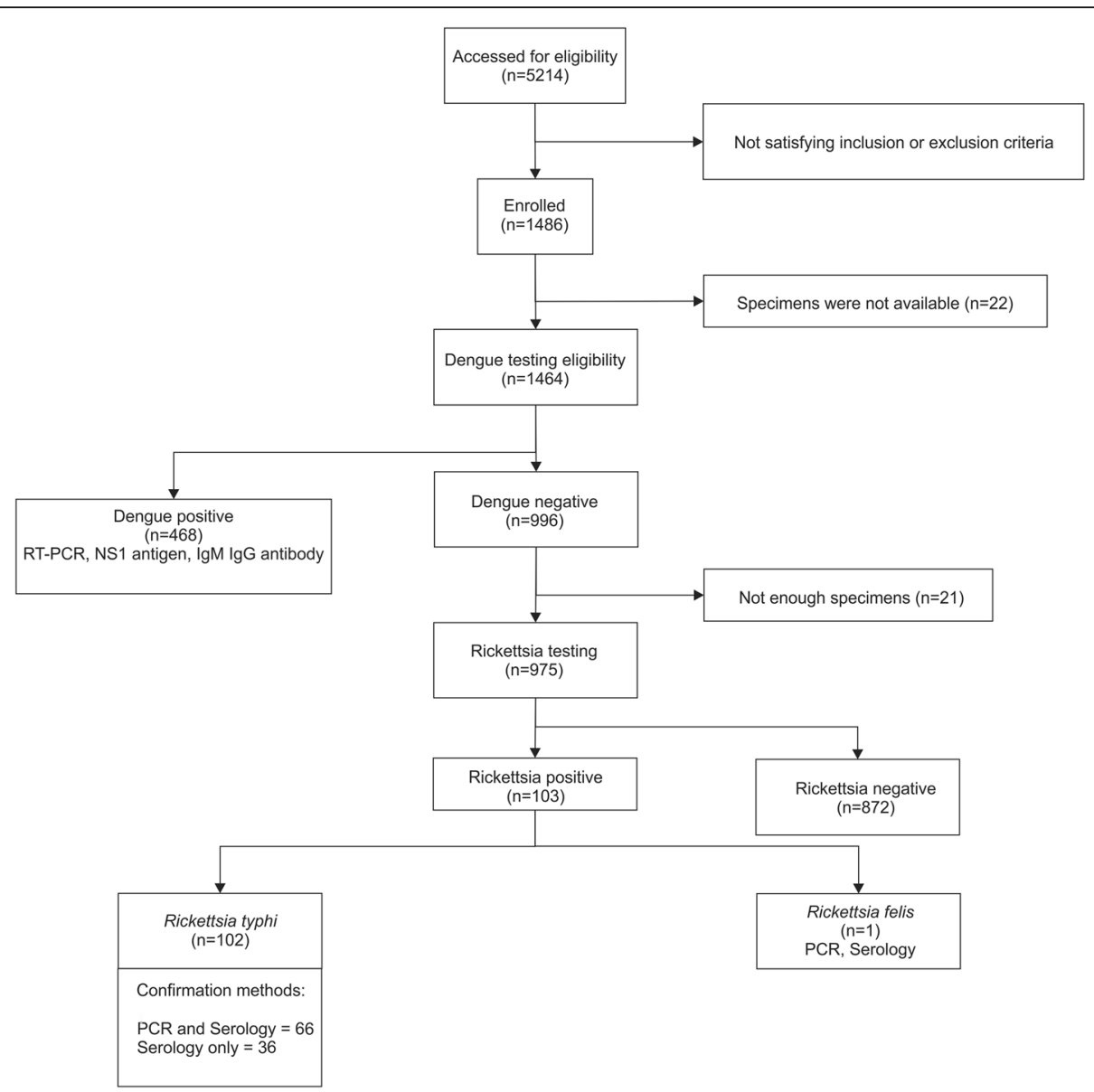

Fig. 1 Diagnostic algorithm to identify Rickettsia infections

Bacterial DNA was extracted using QIAamp DNA mini kit (Qiagen, Hilden, Germany). Rickettsia $s p$. were detected by the $17-\mathrm{kD}$ outer membrane protein $(17-\mathrm{kD}$ omp) gene of Rickettsia sp., while R. typhi was identified by the $o m p \mathrm{~B}$ gene of $R$. typhi following previously published methods $[18,19]$ and $O$. tsutsugamushi by its $47-$ kD omp gene [20]. Specimens positive for 17-KD omp gene of Rickettsia $s p$ but not the $o m p \mathrm{~B}$ gene of $R$. typhi underwent PCR and nested PCR amplification using primer set RompB3503F, RompB4293R, RompB4246R targeting 743-bp sequence of Rickettsia sp. ompB gene and followed by DNA sequencing to determine Rickettsial species [21]. Randomly selected samples with positive $R$. typhi based on qPCR, were confirmed with the same amplification and sequencing method. Sequence chromatograms were edited using BioEdit 7.2.5. software [22]; edited sequences were searched for similarity using BLASTn. Phylogenetic analysis was conducted in MEGA7 and inferred using the Neighbor-Joining method. The analysis involved 704-bp (nucleotide 35564259 of $R$. typhi ompB gene).

\section{Definition for Rickettsia diagnosis}

$R$. typhi infection was confirmed:

1) When both 17-kD omp gene of Rickettsia and $o m p \mathrm{~B}$ gene of $R$. typhi were detected and/or seroconversion or four-fold increase of $R$. typhi IgM and/or IgG by IFA was observed.

2) When the detection of 17-kD omp gene of Rickettsia or omp B gene of R. typhi was supported by DNA sequencing of the 743-bp sequence of Rickettsia sp. omp B gene or sero-conversion or four-fold increase of $R$ typhi IgM and/or IgG by IFA.

Spotted fever group was confirmed by the detection of 17-kD omp gene of Rickettsia and DNA sequencing of the 743-bp sequence of Rickettsia sp.omp B gene and /or sero-conversion or four-fold increase titers of Spotted Fever group IgM and IgG by IFA. Scrub typhus was confirmed by the detection of 47-kD omp gene of O. tsutsugamushi and/or sero-conversion or four-fold increase $O$. tsutsugamushi IgM and/or IgG by ELISA. 


\section{Statistical analysis}

Data were collected in OpenClinica v.3.1 (OpenClinica, LLC) and analyzed using STATA v.15.1 (StataCorp LLC). Clinical and laboratory profiles of confirmed cases were characterized by descriptive statistics and compared according to the three most commonly attributed diagnoses. Proportions were compared between groups using the chi-squared test. The t-test was used to compare means between groups.

\section{Ethical approval}

Ethical approvals were received from IRBs of Dr. Soetomo Hospital (192/Panke.KKE/VIII/2012), Faculty of Medicine Universitas Indonesia Cipto Mangunkusumo Hospital (451/PT02.FK/ETIK/2012) and the National Institute of Health and Research and Development
(NIHRD), Ministry of Health, Indonesia (KE.01.05/EC/ 407/2012).

\section{Results}

Specimens from 975 of 1464 subjects were evaluated using the Rickettsia diagnostic panels. Rickettsia was identified as the etiology of febrile illness in 103/975 (10.6\%) cases (Fig. 1). None of these patients were diagnosed with Rickettsia upon clinical presentation. One case was clinically diagnosed as Rickettsia during hospitalization but was not laboratory confirmed.

Characteristics of patients with acute rickettsial infection at enrollment are shown in Table 1. Of 103 subjects, 69 (67\%) were male and 34 (33\%) female. Median age was 35 years (range: $1-75$ years), with the majority $53 / 103(51.4 \%)$ in patients 19 to 45 years. Underlying diseases were documented in 30 subjects, including

Table 1 Demographics and outcomes ( $n=103$ subjects)

\begin{tabular}{|c|c|}
\hline Median age (range) y.o. & $35(1-75)$ \\
\hline Male: female & 69: 34 \\
\hline \multicolumn{2}{|l|}{ Distribution of cases in age group ${ }^{\mathrm{a}}, \mathrm{N}(\%)$} \\
\hline $1-\leq 5$ years & 2/153 (1.3\%) \\
\hline $6-\leq 18$ years & 19/190 (10\%) \\
\hline $19-\leq 45$ years & $53 / 378(14 \%)$ \\
\hline$>45$ years & $29 / 254(11.4 \%)$ \\
\hline Day of onset (median, range), days & $5(1-12)$ \\
\hline Length of stay (median, range), days & $6(1-36)$ \\
\hline Antibiotics use from 90 subjects with documented history, N (\%) & $76(84 \%)$ \\
\hline Ceftriaxone & $17(22.4 \%)$ \\
\hline Ciprofloxacin & $9(11.8 \%)$ \\
\hline Levofloxacin & $9(11.8 \%)$ \\
\hline Cefixime & $2(2.6 \%)$ \\
\hline Cefotaxime, Amoxicillin, Ampicillin, Cefadroxil, Meropenem, Chloramphenicol, Cefoperazone, Sulbactam, Cotrimoxazole & $1(1.3 \%)$, each \\
\hline Combination 2-3 antibiotics & $30(39.5 \%)$ \\
\hline \multicolumn{2}{|l|}{ Outcomes, N (\%) } \\
\hline Recovered & $72(69.9 \%)$ \\
\hline Recovered with sequelae ${ }^{b}$ & $24(23.3 \%)$ \\
\hline Died & $7(6.8 \%)$ \\
\hline \multicolumn{2}{|l|}{ By sites $^{a}, \mathrm{~N}(\%)$} \\
\hline Bandung & $22 / 189(11.6 \%)$ \\
\hline Denpasar & 16/101 (15.8\%) \\
\hline Jakarta & $7 / 87(8 \%)$ \\
\hline Makassar & 5/131 (3.8\%) \\
\hline Semarang & 21/191 (10.9\%) \\
\hline Surabaya & 26/156 (16.7\%) \\
\hline Yogyakarta & $6 / 120(5 \%)$ \\
\hline
\end{tabular}

afrom 975 subjects tested for Rickettsia typhi

bLethargy, arthralgia, anorexia, headache, dizziness, cough 
diabetes (8), hypertension (8), liver disease (3), respiratory diseases (3), anemia (3), malnutrition (3), HIV (1), and osteoarthritis (1).

\section{Confirmation of rickettsial infections}

The distribution of 103 acute $R$ typhi infection cases by site ranged from 5/131 (3.8\%) in Makassar to 26/156 (16.7\%) in Surabaya. Amongst 872 subjects with no evidence of $\mathrm{R}$ typhi infection, $R$. typhi IgG was detected in 269 (30.8\%) subjects. Spotted fever IgG and O. tsutsugamushi IgG were less common (36/634 (5.7\%) and 19/504 (3.8\%)), respectively. Geographical distribution of IgG prevalence and acute cases is shown in Fig. 2. In 65 of the 103 subjects with acute $R$ typhi infection, confirmation was by Rickettsia $s p$ and/or $R$. typhi DNA and sero-conversion or 4-fold increase titers of IgM and/or IgG IFA. In 36 subjects, diagnosis was based on seroconversion or 4-fold incrase IgM/IgG by IFA. In one subject, $R$. typhi was confirmed by detection of Rickettsia $s p$ and sero-conversion of IgM, IgG by IFA. In the one $R$. felis case, increasing IgG titers to $R$. typhi were detected and $R$. felis DNA was identified by $R$. felis PCR using Rickettsia sp and $R$. felis primers.

Sequencing of $R$. typhi DNA was conducted in 19 specimens. All revealed 99\% sequence identity with $R$. typhi from Myanmar and Thailand (Fig. 3).

\section{Clinical characteristics}

Subjects averaged 5 days (range 1-12 days) of fever before hospital admission (Table 1). Other reported symptoms included nausea (72\%), headache (69\%), vomiting (43\%), lethargy (33\%), anorexia (32\%), arthralgia (30\%), myalgia (28\%), chills (28\%), and epigastric pain (28\%). The clinical triad of $R$. typhi infection (fever, headache and rash) was found in $11 \%$. The three most frequent confirmed diagnoses in the study cohort, dengue, typhoid and leptospirosis demonstrated overlap with rickettsial infection. Details are shown in Table 2.

Most subjects presented with normal hematocrit (median 40.8\%) and leukocyte count (median $7354 / \mathrm{mm}^{3}$ ). The majority had low lymphocyte proportion (median $21.9 \%$ ) and platelets (median $123,426 / \mathrm{mm}^{3}$ ). Mildly increased liver enzymes were found in $77 \%$, with bilirubin increases primarily attributable to direct bilirubin. During hospitalization, no clinically relevant changes were observed.

The hematologic profile of $R$. typhi cases was similar to typhoid, but distinguishable from dengue and leptospirosis. Dengue showed lower leukocyte and platelet counts. Leptospirosis showed higher leukocyte and neutrophil counts, but lower absolute lymphocyte counts. Increased total bilirubin and direct bilirubin were more prevalent than in dengue or typhoid, while increased total and indirect bilirubin were more frequent in

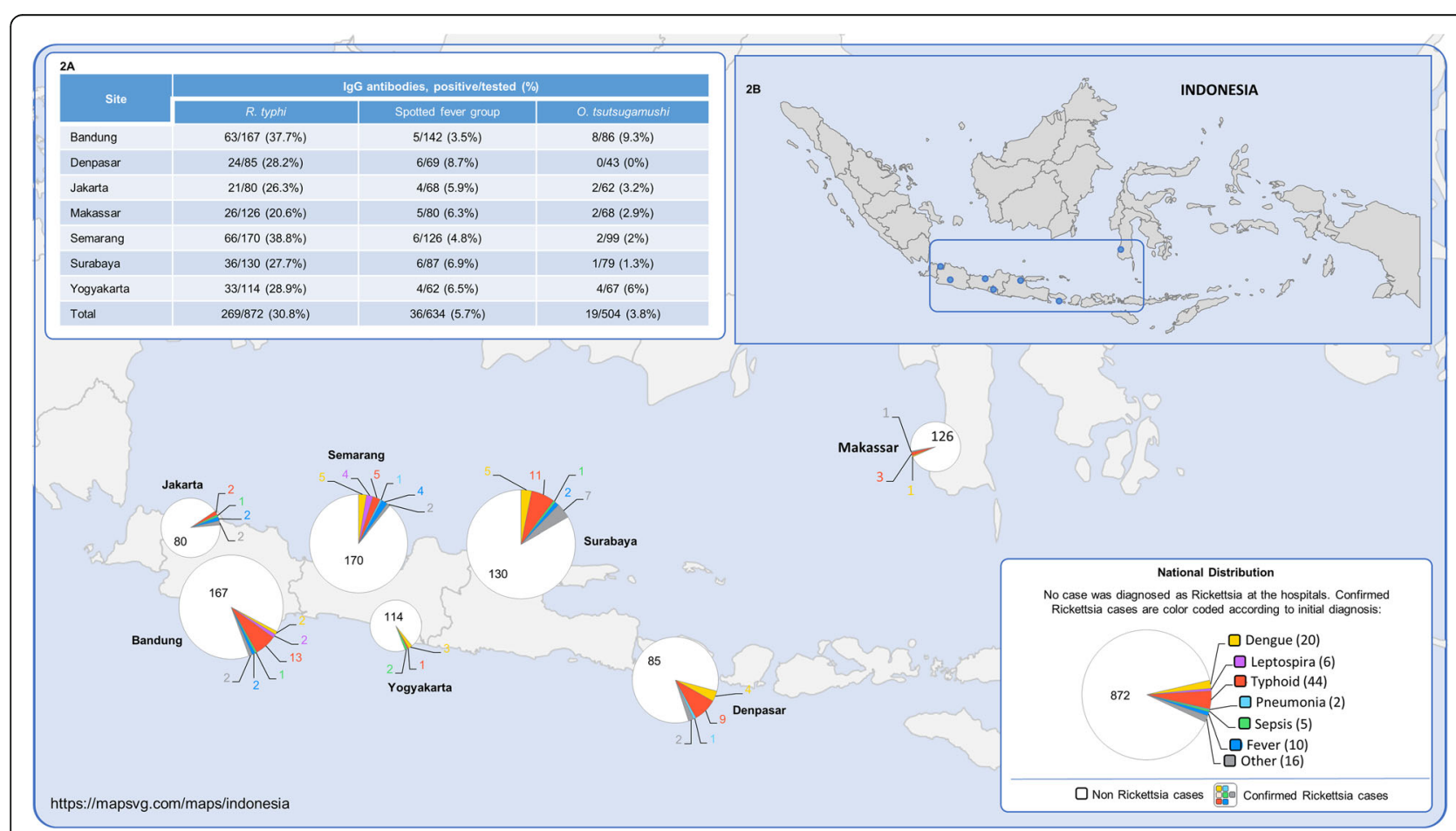

Fig. 2 a Prevalence of IgG antibodies to R. typhi, spotted fever group, and O. tsutsugamushi (positive lgG/Subject tested). b Geographical distribution of acute Rickettsia cases in AFIRE study. Map free source MapSVG. Available from: https://mapsvg.com/maps/indonesia [Accessed 21 March 2020] 


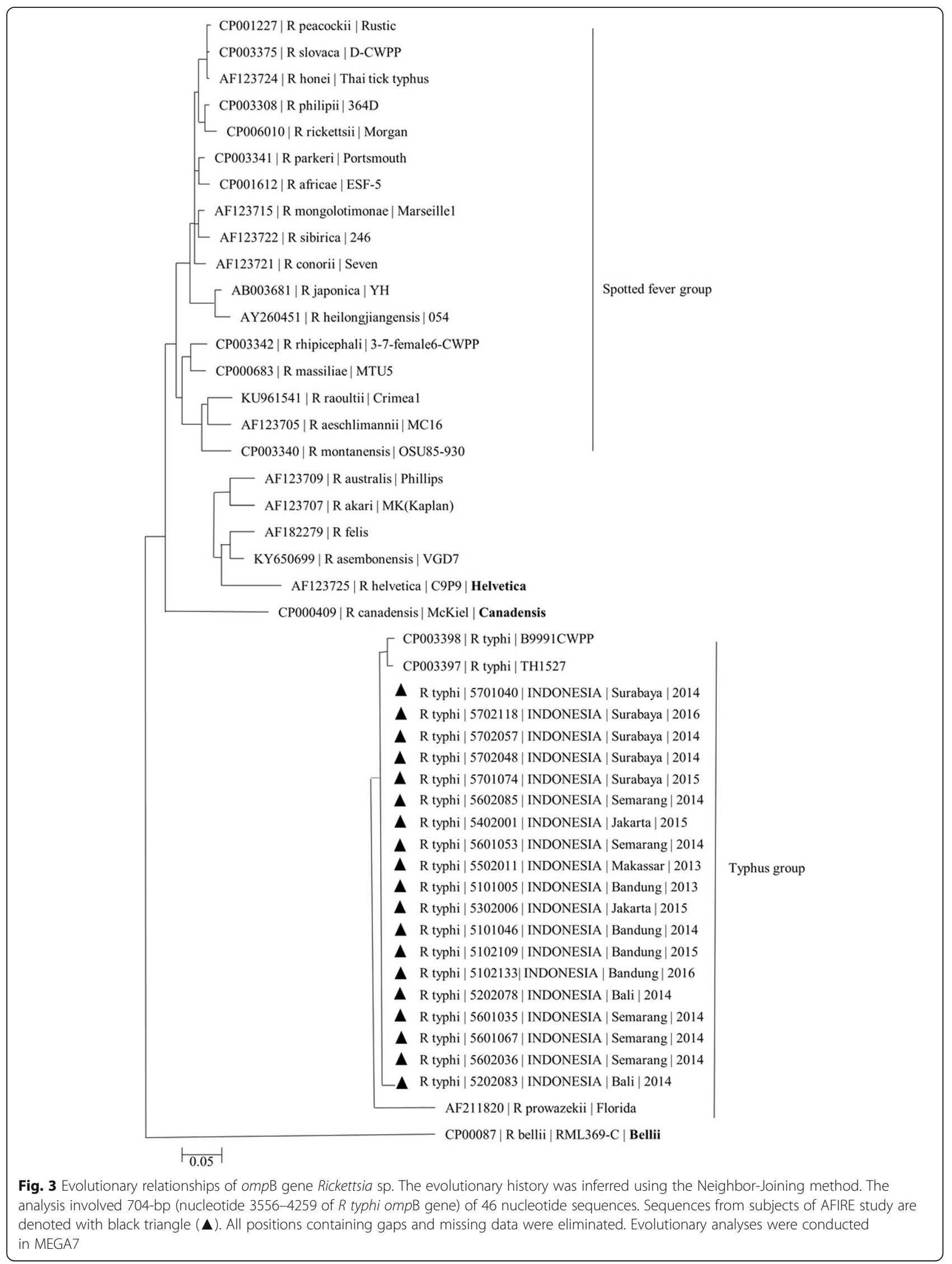


Table 2 Characteristics of $R$. typhi cases, compared to dengue, S. typhi, and leptospira cases

\begin{tabular}{|c|c|c|c|c|}
\hline Clinical signs and symptoms & $\begin{array}{l}\text { R. typhi cases } \\
N=102^{\dagger}\end{array}$ & $\begin{array}{l}\text { Dengue cases } \\
N=468\end{array}$ & $\begin{array}{l}\text { Salmonella cases } \\
N=103\end{array}$ & $\begin{array}{l}\text { Leptospira cases } \\
N=48\end{array}$ \\
\hline \multicolumn{5}{|l|}{ Symptoms, N (\%) } \\
\hline Fever & $102(100)$ & $468(100)$ & $103(100)$ & $48(100)$ \\
\hline Nausea & $73(72)$ & $345(74)$ & $74(72)$ & $38(76)$ \\
\hline Anorexia & $33(32)^{b}$ & $153(33)$ & $49(48)$ & $16(33)$ \\
\hline Headache & $70(69)^{a b}$ & $261(56)$ & $45(44)$ & $26(54)$ \\
\hline Vomiting & $44(43)$ & $249(53)$ & $52(50)$ & $29(60)$ \\
\hline Lethargy & $34(33)^{a}$ & $102(22)$ & $46(45)$ & $14(29)$ \\
\hline Arthralgia & $31(30)$ & $139(30)$ & $25(24)$ & $19(40)$ \\
\hline Myalgia & $29(28)$ & $103(22)$ & $20(19)$ & $20(42)$ \\
\hline Chills & $29(28)^{a}$ & $65(14)$ & $35(34)$ & $20(42)$ \\
\hline Epigastric pain & $29(28)$ & $112(24)$ & $32(31)$ & $12(25)$ \\
\hline Cough & $24(24)^{b}$ & $79(17)$ & $48(47)$ & $16(33)$ \\
\hline Diarrhea & $15(15)^{b c}$ & $47(10)$ & $41(40)$ & $20(42)$ \\
\hline Skin rash & $17(17)^{b}$ & $85(18)$ & $3(3)$ & $3(6)$ \\
\hline Constipation & $19(19)^{a}$ & $23(5)$ & $15(15)$ & $6(13)$ \\
\hline Altered mental status & $4(4)^{a}$ & $6(1)$ & $3(3)$ & $1(2)$ \\
\hline Dysuria & $4(4)$ & $9(2)$ & $1(1)$ & $3(6)$ \\
\hline Icterus & $5(5)$ & $2(0.4)$ & $1(1)$ & $6(13)$ \\
\hline Rickettsia Triad: fever, headache and rash & $11(11)^{\mathrm{b}}$ & $57(12)$ & $2(2)$ & $1(2)$ \\
\hline \multicolumn{5}{|l|}{ Hematology profiles: Mean (SD) } \\
\hline $\mathrm{Hb}(\mathrm{mg} / \mathrm{dl})$ & $14.04(1.89)^{b c}$ & $13.9(1.84)$ & $12.4(1.79)$ & $13.3(2.06)$ \\
\hline Hematocrit (\%) & $40.8(5.18)^{b}$ & $41(5.21)$ & $36.3(5.42)$ & $38.9(6.16)$ \\
\hline Leukocyte count: $/ \mathrm{mm}^{3}$ & $7354(2975)^{a c}$ & $4225(2608)$ & $6902(2974)$ & $10,924(4246)$ \\
\hline Platelet count & $123,426(61,746)^{a b}$ & $107,720(67,522)$ & $158,402(74,784)$ & $138,333(75,491)$ \\
\hline \multicolumn{5}{|l|}{ N (\%) } \\
\hline Leukopenia & $14(14)^{\mathrm{ac}}$ & $312(66.7)$ & $21(20)$ & $2(4.2)$ \\
\hline Leukocytosis & $17(17)^{a}$ & $9(1.9)$ & $12(11.7)$ & $25(24.5)$ \\
\hline Platelet $<100,000 / \mathrm{mm}^{3}$ & $41(40)^{a b}$ & $266(57)$ & $22(21)$ & $13(27)$ \\
\hline Platelet $<150,000 / \mathrm{mm}^{3}$ & $74(73)$ & $373(8)$ & $52(50)$ & $26(54)$ \\
\hline Thrombocytopenia $(150,000)$ AND leukopenia $(<5000)$ & $19(19)^{a c}$ & $318(68)$ & $22(21)$ & 0 \\
\hline \multicolumn{5}{|l|}{ Leucocyte cell types; Mean (SD) } \\
\hline Neutrophil (\%) & $70.34(10.87)^{a b c}$ & $60.59(16.41)$ & $64.8(14.2)$ & $84.2(7.9)$ \\
\hline Neutrophil count & $5329(2741)^{a b c}$ & $2672(2227)$ & $4373(2216)$ & $9001(3453)$ \\
\hline Lymphocyte (\%) & $21.9(9.85)^{a b c}$ & $28.5(15.1)$ & $26.5(12.2)$ & $9.5(6.4)$ \\
\hline Lymphocyte absolute & $1388(484-4489)$ & $888(192-7104)$ & $1521(348-10,900)$ & $729(243-2783)$ \\
\hline \multicolumn{5}{|l|}{$\mathrm{N}(\%)$} \\
\hline Neutropenia & $9(9)$ & $99(21)$ & $17(17)$ & 0 \\
\hline Neutrophilia & $12(12)^{c}$ & $41(9)$ & $14(14)$ & $22(46)$ \\
\hline Lymphocytopenia & $31(30)$ & $110(24)$ & $26(25)$ & $32(67)$ \\
\hline Lymphocytosis & $8(8)$ & $84(18)$ & $17(17)$ & 0 \\
\hline \multicolumn{5}{|l|}{ Biochemistry profiles: Median (range) } \\
\hline Bilirubin (mg/dl) & $0.55(0.12-12)$ & $0.37(0.08-3.46)$ & $0.37(0.1-2.09)$ & $0.69(0.13-16.83)$ \\
\hline $\mathrm{ALT}(\mathrm{IU})$ & $82(12-604)$ & $83(1-6570)$ & $66(14-542)$ & $38(15-207)$ \\
\hline
\end{tabular}


Table 2 Characteristics of R. typhi cases, compared to dengue, S. typhi, and leptospira cases (Continued)

\begin{tabular}{|c|c|c|c|c|}
\hline \multirow[t]{2}{*}{ Clinical signs and symptoms } & R. typhi cases & Dengue cases & Salmonella cases & Leptospira cases \\
\hline & $N=102^{\dagger}$ & $N=468$ & $N=103$ & $N=48$ \\
\hline AST (IU) & $69(0.71-466)$ & $34(1-1286)$ & $40(5-339)$ & $32(10-141)$ \\
\hline Urea (mg/dl) & $26(9-181.2)$ & $17(0.3-121)$ & $19(6-59)$ & $53(13-459)$ \\
\hline Creatinine (mg/dl) & $0.9(0.4-9.92)$ & $0.85(0.05-98)$ & $0.7(0.3-1.7)$ & $1.2(0.5-8.8)$ \\
\hline \multicolumn{5}{|l|}{ N/available data (\%) } \\
\hline Bilirubin $>1 \mathrm{mg} / \mathrm{dl}$ & $21 / 98(21) a b c$ & $10 / 409(2)$ & $5 / 96(5)$ & $17 / 46(37)$ \\
\hline Direct bilirubin $>0.4$ mg/dl & $36 / 98(37)^{a b c}$ & $27 / 409(7)$ & 13/96 (14) & $26 / 46(56)$ \\
\hline Indirect bilirubin $>0.6 \mathrm{mg} / \mathrm{dl}$ & $7 / 98(7)^{c}$ & $17 / 409(4)$ & 2/96 (5) & $10 / 46(22)$ \\
\hline Direct $>$ Indirect bilirubin & $66 / 98(67)^{a}$ & $147 / 409(36)$ & $55 / 97(57)$ & $34 / 46(74)$ \\
\hline $\mathrm{ALT}>45 \mathrm{IU}$ & 76/97 (78) & $326 / 409(80)$ & 65/95 (68) & $16 / 45(36)$ \\
\hline ALT $>100 \mathrm{IU}$ & $35 / 97(36)^{c}$ & $147 / 409(36)$ & 26/95 (27) & $7 / 45(16)$ \\
\hline AST $>35 \mathrm{IU}$ & 75/97 (77) & 197/409 (48) & $54 / 97(56)$ & $16 / 45(36)$ \\
\hline AST $>100 \mathrm{IU}$ & $28 / 97(29)$ abc & $60 / 409(15)$ & $7 / 97(7)$ & $2 / 45(4)$ \\
\hline Urea $N>40 \mathrm{mg} / \mathrm{dl}$ & $4 / 31(13)^{a c}$ & $10 / 409(2)$ & 4/44 (9) & 24/44 (55) \\
\hline Creatinine $>1.2 \mathrm{mg} / \mathrm{dl}$ & $15 / 98(15)^{b c}$ & $44 / 409(11)$ & $5 / 94(5)$ & $25 / 46(54)$ \\
\hline
\end{tabular}

Note: Significant $(p<0.05)^{a}$ between R. typhi and dengue, ${ }^{b}$ between $R$. typhi and S. typhi, ${ }^{c}$ between $R$. typhi and leptospira. tOne Rickettsia felis case is not included

leptospirosis. AST above $100 \mathrm{IU}$ was more common in $R$. typhi cases compared to the three diseases, whereas creatinine $>1.2 \mathrm{mg} / \mathrm{dl}$ was more common in leptospirosis.

\section{Clinical diagnoses}

For the 103 rickettsioses patients, discharge diagnoses were: typhoid fever (44), dengue fever (20), leptospirosis (6), respiratory infections (1 upper, and 6 lower), unidentified fever (6), sepsis (6), hepatobiliary infections (3), unidentified viral infections (3), UTI (3) and others (one each: HIV, chikungunya, enteritis, meningoencephalitis, and diabetic neuropathy).

In all cases of Rickettsia initially suspected to be leptospirosis, typhoid fever, chikungunya, or dengue fever, diagnostic assays for those pathogens at the reference laboratory were negative, except in one $R$. felis case where leptospira PCR was positive and leptospira IgM and IgG sero-converted, suggesting co-infection. Clinicians diagnosed typhoid despite negative or weak positive S. typhi IgM rapid tests in 24 presumed typhoid cases; in 4 other cases rapid tests were not performed. In the remaining cases [16], positive results from the rapid test were not supported as blood culture, PCR and ELISA IgM tests for Salmonella were negative. In these 16 cases, R. typhi was confirmed by PCR and/or serological assays. Fifteen dengue diagnoses were not supported by rapid dengue antigen or antibody tests. In contrast, 6 presumed leptospirosis cases had positive rapid tests, but PCR and ELISA at the reference laboratory were negative except in the $R$. felis case above. Details of the diagnostic tests to confirm Rickettsia infection and to exclude S. typhi, dengue, and Leptospira infections are shown in additional file (see Additional file: Table S1).

\section{Management and outcomes}

Antibiotics were taken prior to hospitalization in 23 subjects, including amoxicillin (8), cephadroxil (4), cotrimoxazole (3), chloramphenicol (2), cefixime (1), spiramycin (1), and a combination of antibiotics (4). Antibiotics were given at hospitals in 76 of 90 (84\%) subjects with documented treatment data as shown in Table 1 . The majority received ceftriaxone (17), ciprofloxacin (9) and levofloxacin (9), or a combination of antibiotics (30). The drug of choice for Rickettsia infection, doxycycline was given to 2 patients, one in combination with ceftriaxone and one with amoxicillin. 14 (58\%) subjects with suspected viral infections received antibiotics at hospital several days after no clinical improvement with symptomatic treatment. The median hospital stay was 6 days (range 1-36).

Twenty-four subjects (23.3\%) recovered with sequelae and $72(69.9 \%)$ recovered without sequelae. Seven (6.8\%) patients (median 54.7 years, range $36.1-75$ years) died. Of these, 5 had underlying disease (stroke, HIV and chronic liver disease, HIV and TB, DM, and COPD). Six deaths were attributed to sepsis; in one HIV positive patient with meningoencephalitis, death was attributed to cardiogenic shock. All patients who died received antibiotics, however none received doxycycline. Contribution of rickettsial infection to these deaths could not be ascertained. 


\section{Discussion}

Our results confirm that rickettsial infections are an important, and often overlooked, cause of fever in hospitalized patients in Indonesia. The prevalence of subjects with $R$. typhi IgG was unexpectedly high (30.8\%), suggesting significant population exposure. Furthermore, acute rickettsial infection was the etiology of acute febrile illness in $10.6 \%$ of hospitalized subjects, none of whom were clinically diagnosed or managed as having rickettsial infection during hospitalization.

The most common clinical manifestations in our subjects (fever, headache, and nausea/vomiting) have been reported in other studies [23, 24]. However, rash, the hallmark of ricketsial disease diagnosis that usually occurs late (around 5 days of illness in patients with murine typhus) [11] was less common than other reports (17\% vs. 12 to $80 \%$, respectively) [24, 25]. This may be attributable to the design of the AFIRE study, which only recorded clinical signs and symptoms of subjects during admission, while other studies monitored them throughout illness. Lack of longitudinal monitoring may explain why prevalence of the $R$. typhi infection clinical triad was lower in our study (11\%) than in other studies (4964\%) $[26,27]$.

Several factors may contribute to the misdiagnosis of rickettsioses during hospitalization. First, presentation of Rickettsia infection overlaps with that of other infectious etiologies, particularly typhoid fever, as demonstrated in our study and by data from the US CDC [7]. Second, clinicians may not include rickettsioses in their differential diagnosis. Literature demonstrating the importance of Rickettsia infection in the hospital setting is lacking. Previous reports were from a few serologically-confirmed patients from three cities in 1976, 1996 [28], 1997-2000 [9], 2006 [10] and may not have reached clinicians. Third, access to diagnostic tests for rickettsioses is poor and specificity is low for available rapid diagnostics for other pathogens such as S. typhi, dengue virus and Leptospira spp. Reports from Laos also describe difficulties in differentiating these 4 pathogens [29].

Prior reports also suggest that rickettsioses are an important etiology of fever in Indonesia. A hospital-based study by Groen et al. in Semarang, Central Java found rickettsioses in 7 of 118 (6\%) suspected dengue cases during 1995-1996 [28]. A fever study by Gasem et al. in the same city 10 years later reported 20 Rickettsia cases amongst 127 children and adults visiting primary health centers and hospitals. It is unclear if these cases were due to $R$. typhi [10]. As part of a dengue vaccine study, Copeding et al. found that $7 \%$ of childhood fever was caused by Rickettsia, based on ELISA IgM [8].

Previous studies have typically confirmed rickettsioses by serologic assays only. Our study applied a panel of diagnostic assays including molecular assays, ELISA, and
IFA, and therefore provides additional information about Rickettsia subgroups, as well as the acutely infecting species. Furthermore, this study demonstrated the occurrence of human rickettsiosis in geographical areas excluded from previous studies (Yogyakarta, Surabaya, and Makassar) and reconfirmed that rickettsioses continue to circulate in Semarang, Bandung, Jakarta, and Bali, both in children and adults.

Although the prevalence of rickettsioses in Indonesia was as high as in Thailand or Malaysia, predominant species differed. In our study, $R$. typhi was most common, whereas in Thailand and Malaysia O. tsutsugamushi was more frequent [30, 31]. As O. tsutsugamushi has been found in hosts and vectors from several areas in Indonesia and evidence of previous infection was detected in our samples, we likely underdiagnosed scrub typhus. This may be because our study did not include primary health centers, where cases of O. tsutsugamushi may be managed [9]. It is also possible that there are factors, such as exposure or genetic constitution, in our population that predispose to murine typhus [32].

In $70 \%$ of subjects initially diagnosed as typhoid fever or dengue fever, diagnoses were unchanged despite subsequent negative or doubtful rapid test results, suggesting that in the absence of comprehensive diagnostic tests, clinicians had no choice but to judge based on the clinical presentations. In 16 cases with positive $(\geq 4)$ rapid test, the detection of IgM may be associated with persistent IgM that can be detected more than a year after infection [33] and/or multiple exposure for people living in endemic area [34]. In contrast, the six initially suspected leptospirosis cases had positive Leptospira IgM, although reference laboratory confirmatory antibody testing and PCR were negative, except in one case with possible co-infection. This suggests that severe $R$. typhi may clinically resemble leptospirosis (myalgia, abdominal pain, icterus) [29] and clinicians should interpret the results of leptospira antibody tests cautiously. Poor specificity of the Leptospira IgM test, both with rapid testing and ELISA, has been reported [35]. Leukocyte count may also help differentiate between rickettsiosis and leptospirosis as it is more likely to be leukocytosis in leptospirosis.

The case fatality rate of $R$. typhi infection in our study (6.8\%) is higher than previously reported (0.3 to $4 \%$ ) [28-30]. Our study's higher mortality may be related to presence of comorbidities in 5 of the 7 fatal cases. However, we cannot exclude the possibility of severe $R$. typhi. Complications including meningitis and encephalitis, acute respiratory distress syndrome, acute liver failure, acute renal failure, endocarditis, and multi-organ failure have been reported [36].

Diagnostic inaccuracy can result in inappropriate management of patients. Ideally, rickettsioses should be 
quickly identified and doxycycline, the antibiotic of choice, administered. Amongst patients with rickettsial infection in the AFIRE study, two subjects initially diagnosed as leptospirosis received doxycycline in combination with other antibiotics. In $58 \%$ of suspected viral infection subjects, antibiotics were later given, suggesting that clinicians considered bacterial infections but had difficulty making definitive diagnoses.

Broad spectrum antibiotics such as ceftriaxone or ciprofloxacin are effective against rickettsioses and are reasonable empiric choices while awaiting laboratory confirmation given the overlap of clinical presentations of Rickettsia and other infections. However, unnecessary administration of broad spectrum antibiotics should be discouraged. Appropriately targeted treatment could hasten recovery, reduce healthcare utilization, and minimize development of antibiotic resistance [37, 38]. On the other end of the antimicrobial stewardship spectrum, misdiagnosis of rickettsial infection as dengue could result in witholding necessary antibiotics. This is of particular concern in environments where dengue, which is managed supportively, is diagnosed empirically without laboratory confirmation and Rickettsia is not considered.

Policy makers and clinicians should prioritize diagnosis, treatment and prevention of rickettsioses in Indonesia. Improved detection with subsequent appropriate management could decrease patient morbidity and reduce healthcare costs. Ideally, laboratories should be equipped with valid diagnostic assays (PCR for molecular detection during acute illness and IFA as the gold standard for serology). However, PCR and IFA have several disadvantages, including the need for an expensive thermal cycler or a fluorescence microscope, which are often unavailable in endemic resource-limited settings, and experienced technicians [39]. Therefore, ELISA can be an alternative when both are unavailable [40]. Proper empiric management, including administration of appropriate antibiotics, and early diagnostic strategies will minimize disease sequelae. Finally, development and implementation of prevention guidelines may also reduce disease burden.

Our study had several limitations. First, we only enrolled hospitalized patients with fever, and therefore the results cannot be generalized to cases not requiring hospitalization. Second, this study was conducted in 7 large Indonesian cities, so may not reflect what is seen in more rural areas or other cities. Finally, as the parent AFIRE study was not designed as a Rickettsia study, we did not specifically collect clinical data or request laboratory tests targeting rickettsial infections. To address this limitation, we retrospectively reviewed medical records for additional data not recorded in case report forms. Lastly, we do not know that outcomes would be different if cases had been diagnosed and appropriate targeted treatment provided.

\section{Conclusions}

In conclusion, our study demonstrates the importance of including rickettsioses in the differential diagnosis for fever in hospitalized patients, developing laboratory capacity and point of care test to rapidly and accurately diagnose rickettsioses, and implementing public policy to reduce disease burden. Further studies should be conducted to better characterize the epidemiology of rickettsioses in Indonesia and evaluate outcomes when appropriate empiric and targeted therapy are provided.

\section{Supplementary information}

Supplementary information accompanies this paper at https://doi.org/10 1186/s12879-020-05057-9.

Additional file 1: Table S1. Diagnostic tests to confirm rickettsia infection and to exclude S. typhi, Dengue, Leptospira, and Chikungunya infections and diagnostic tests to confirm rickettsia infection in an HIV patient and 31 patients with non-rickettsial clinical diagnoses.

\section{Abbreviations}

AFIRE: The etiology of acute febrile illness requiring hospitalization; AST: Aspartate transaminase; ALT: Alanine transaminase; BLAST: Basic local alignment search tool; CDC: Centers for disease control and prevention; COPD: Chronic obstructive pulmonary disease; DNA: Deoxyribonucleic acid; DM: Diabetes mellitus; ELISA: enzyme-linked immunosorbent assay; HIV: Human immunodeficiency virus; IFA: Immunofluorescence assay; INARESPOND: Indonesia research partnership on infectious diseases;

IU: International unit; PCR: Polymerase chain reaction; TB: Tuberculosis; UTI: Urinary tract infection

\section{Acknowledgements}

We would like to thank our patients and their families for support of this study and nurses and laboratory technicians for collecting and testing the specimens at sites. We thank Dr. Richards and Dr. Widjaja for advice on appropriate Rickettsial testing and reference laboratory team (Gustiani, Ungke Anton Jaya, Deni Pepi Butarbutar, Wahyu Nawang Wulan, Yuanita Djajadi, Rizki Amalia Sari) for testing the specimens. We also would like to thank Antonius Arditya Pradana and Aly Diana for technical assistance with the manuscript.

\section{Authors' contributions}

Study design: DL, UH, CYL, HK, CJL, MR, PS, NL, KL, RHA, DM, IMS, RHM, MK, MHG, BA. Clinical evaluation: $\mathrm{DL}, \mathrm{UH}, \mathrm{CYL}, \mathrm{HK}, \mathrm{CJ}, \mathrm{MR}, \mathrm{PS}, \mathrm{NL}, \mathrm{RHA}, \mathrm{DM}, \mathrm{IMS}$, $\mathrm{RHM}, \mathrm{MK}, \mathrm{MHG}, \mathrm{BA}$. Laboratory testing: DL, HK. Data analysis and manuscript preparation: DL, UH, CYL, HK, CJL, MR, PS, NL, KL, RHA, DM, IMS, RHM, MK, $\mathrm{MHG}, \mathrm{BA}$. All authors have read and approved the final manuscript.

\section{Funding}

This study was conducted by INA-RESPOND, a collaborative research network of NIHRD, Ministry of Health, Indonesia, and US-NIAID, NIH. This project has been funded in whole or in part with Federal funds from the NIAID, NIH, under contract Nos. HHSN261200800001E and HHSN261201500003I. NIAID collaborators contributed to design of the study; collection, analysis, and interpretation of data; and writing of the manuscript. The content of this publication does not necessarily reflect the views or policies of the Department of Health and Human Services, nor does mention of trade names, commercial products, or organizations imply endorsement by the U.S. Government.

\section{Availability of data and materials}

The datasets used and/or analysed during the current study are available from the corresponding author on reasonable request. 


\section{Ethics approval and consent to participate}

All subjects provided written informed consent before study participation. The study was conducted in accordance with the Declaration of Helsinki, and the protocol was approved by the IRBs of Faculty of Medicine, University of Indonesia/ Dr. Cipto Mangunkusumo Hospital (451/PT02.FK/ETIK/2012), Dr. Soetomo Hospital (192/Panke.KKE/VIII/2012), and the National Institute of Health and Research and Development (NIHRD), Ministry of Health, Indonesia (KE.01.05/EC/407/2012).

\section{Consent for publication}

Not applicable.

\section{Competing interests}

The authors declare that they have no competing interests.

\begin{abstract}
Author details
${ }^{1}$ Tangerang District Hospital, Tangerang, Indonesia. ${ }^{2}$ Indonesia Research Partnership on Infectious Disease (INA-RESPOND), Badan Litbangkes, Building 4, 5th floor, Jl Percetakan Negara no 29, Jakarta 10560, Indonesia. ${ }^{3}$ Dr. Soetomo Academic General Hospital - Faculty of Medicine Universitas Airlangga, Surabaya, Indonesia. ${ }^{4}$ National Institute of Allergy and Infectious Disease (NIAID), National Institutes of Health, Bethesda, MD, USA. ${ }^{5}$ Cipto Mangunkusumo Hospital, Jakarta, Indonesia. ' ${ }^{6}$ ardjito Hospital, Yogyakarta, Indonesia. ${ }^{7}$ Sulianti Saroso Hospital, Jakarta, Indonesia. ${ }^{8}$ Sanglah General Hospital, Denpasar, Bali, Indonesia. ' Wahidin Sudirohusodo Hospital, Makassar, Indonesia. ${ }^{10}$ National Institute of Health Research and Development (NIHRD), Ministry of Health Republic of Indonesia, Jakarta, Indonesia. ${ }^{11}$ Dr. Kariadi Hospital - Diponegoro University, Semarang, Indonesia. ${ }^{12}$ Hasan Sadikin Hospital - Faculty of Medicine Universitas Padjadjaran, Bandung, Indonesia.
\end{abstract}

Received: 2 February 2020 Accepted: 28 April 2020

Published online: 24 May 2020

\section{References}

1. Raoult D, Roux V. Rickettsioses as paradigms of new or J Emer Infect Dis. Clin Microbiol Rev. 1997;10(4):694-719.

2. Faccini-Martinez AA, Garcia-Alvarez L, Hidalgo M, Oteo JA. Syndromic classification of rickettsioses: an approach for clinical practice. Int J Infect Dis. 2014;28:126-39.

3. Kato H, Yanagisawa N, Sekiya N, Suganuma A, Imamura A, Ajisawa A. Murine typhus in a Japanese traveler returning from Indonesia: a case report. Kansenshogaku Zasshi. 2014:88(2):166-70.

4. Parola P, Vogelaers D, Roure C, Janbon F, Raoult D. Murine typhus in travelers returning from Indonesia. J Emer Infect Dis. 1998;4(4):677-80.

5. Stockdale AJ, Weekes MP, Kiely B, Lever AM. Case report: severe typhus group rickettsiosis complicated by pulmonary edema in a returning traveler from Indonesia. Am J Trop Med Hyg. 2011;85(6):1121-3.

6. Jensenius M, Fournier PE, Raoult D. Rickettsioses and the international traveler. Clin Infect Dis. 2004;39(10):1493-9.

7. Nicholson WL, and Paddock CD. Rickettsial (spotted \& typhus fevers) \& related infections, including anaplasmosis \& ehrichiosis. Center for Disease Control and Prevention. 2017. Available from: www.cdcgov/ticks. Accessed Aug 2017.

8. Capeding MR, Chua MN, Hadinegoro SR, Hussain II, Nallusamy R, Pitisuttithum P, et al. Dengue and other common causes of acute febrile illness in Asia: an active surveillance study in children. PLoS Negl Trop Dis. 2013;7(7):e2331.

9. Punjabi NH, Taylor WR, Murphy GS, Purwaningsih S, Picarima H, Sisson J, et al. Etiology of acute, non-malaria, febrile illnesses in Jayapura, northeastern Papua, Indonesia. Am J Trop Med Hyg. 2012;86(1):46-51.

10. Gasem MH, Wagenaar JF, Goris MG, Adi MS, Isbandrio BB, Hartskeerl RA et al. Murine typhus and leptospirosis as causes of acute undifferentiated fever, Indonesia. J Emerg Infect Dis. 2009;15(6):975-7.

11. Center for Disease Control and Prevantion. Typhus fevers: flea-borne (murine) typhus. CDC. 2019. Available from: https://www.cdc.gov/typhus/ murine/index.html.

12. Lee N, Ip M, Wong B, Lui G, Tsang OWTY, Lai JY, Choi KW, Lam R, Ng TK, Ho J, Chan YY, Cockram CS, Lai ST. Risk factors associated with life-threatening. Am J Trop Med Hyg. 2008;78(6):973-8.
13. Gasem MH, Kosasih H, Tjitra E, Alisjahbana B, Karyana M, Lokida D, et al. An observational prospective cohort study of the epidemiology of hospitalized patients with acute febrile illness in Indonesia. PLoS Negl Trop Dis. 2020; 14(1):e0007927.

14. Karyana M, Kosasih H, Samaan G, Tjitra E, Aman AT, Alisjahbana B, et al. INARESPOND: a multi-centre clinical research network in Indonesia. Health Res Policy Syst. 2015;13:34

15. Kantso B, Svendsen CB, Jorgensen CS, Krogfelt KA. Evaluation of serological tests for the diagnosis of rickettsiosis in Denmark. J Microbiol Methods. 2009;76(3):285-8.

16. Blacksell SD, Kingston HWF, Tanganuchitcharnchai A, Phanichkrivalkosil M, Hossain M, Hossain A, et al. Diagnostic accuracy of the InBios Scrub typhus detect ELISA for the detection of IgM antibodies in Chittagong, Bangladesh. Trop Med Infect Dis. 2018;3(3):95.

17. Center for Disease Control and Prevantion. Rocky Mountain Spotted Fever (RMSF): clinical and laoratory diagnosis. CDC. 2018. Available from: https:// www.cdc.gov/rmsf/healthcare-providers/ClinLab-Diagnosis. html\#anchor_1533217926192.

18. Henry KM, Jiang J, Rozmajzl PJ, Azad AF, Macaluso KR, Richards AL. Development of quantitative real-time PCR assays to detect Rickettsia typhi and Rickettsia felis, the causative agents of murine typhus and flea-borne spotted fever. Mol Cell Probes. 2007;21(1):17-23.

19. Wright $\mathrm{CL}$, Nadolny RM, Jiang J, Richards AL, Sonenshine DE, Gaff HD, Hynes WL. Rickettsia parkeri in gulf coast ticks, southeastern Virginia, USA. J Emer Infect Dis. 2011;17(5):896-8.

20. Jiang J, Chan TC, Temenak JJ, Dasch GA, Ching WM, Richards AL. Development of a quantitative real-time polymerase chain reaction assay specific for Orientia tsutsugamushi. Am J Trop Med Hyg. 2004;70(4):351-6.

21. Maina AN, Klein TA, Kim H-C, Chong S-T, Yang Y, Mullins K, et al. Molecular characterization of novel mosquito-borne Rickettsia spp. from mosquitoes collected at the Demilitarized Zone of the Republic of Korea. PLoS One. 2017;12(11):e0188327.

22. Hall TA, editor. BioEdit: a user-friendly biological sequence alignment editor and analysis program for Windows 95/98/NT. Nucleic acids symposium series. London: Information Retrieval Ltd; 1999. p. c1979-2000.

23. Huntzinger A. Guidelines for the diagnosis and treatment of tick-borne rickettsial diseases. Am Fam Physician. 2007;76(1):137-9.

24. Civen R, Ngo V. Murine typhus: an unrecognized suburban vectorborne disease. Clin Infect Dis. 2008;46(6):913-8.

25. Walter G, Botelho-Nevers E, Socolovschi C, Raoult D, Parola P. Murine typhus in returned travelers: a report of thirty-two cases. Am J Trop Med Hyg. 2012; 86(6):1049-53.

26. Whiteford SF, Taylor JP, Dumler JS. Clinical, laboratory, and epidemiologic features of murine typhus in 97 Texas children. Arch Pediatr Adolesc Med. 2001;155(3):396-400.

27. Chaliotis G, Kritsotakis El, Psaroulaki A, Tselentis Y, Gikas A. Murine typhus in central Greece: epidemiological, clinical, laboratory, and therapeuticresponse features of 90 cases. Int J Infect Dis. 2012;16(8):e591-6.

28. Groen J, Koraka P, Osterhaus A, Suharti C, van Gorp E, Sutaryo J, et al. Serological evidence of human hantavirus infections in Indonesia. Infection. 2002;30(5):326-7.

29. Phongmany S, Rolain JM, Phetsouvanh R, Blacksell SD, Soukkhaseum V, Rasachack B, et al. Rickettsial infections and fever, Vientiane, Laos. J Emer Infect Dis. 2006;12(2):256-62.

30. Suputtamongkol Y, Suttinont C, Niwatayakul K, Hoontrakul S, Limpaiboon R, Chierakul W, et al. Epidemiology and clinical aspects of rickettsioses in Thailand. Ann N Y Acad Sci. 2009;1166:172-9.

31. Brown GW, Shirai A, Jegathesan M, Burke DS, Twartz JC, Saunders JP, et al. Febrile illness in Malaysia--an analysis of 1,629 hospitalized patients. Am J Trop Med Hyg. 1984;33(2):311-5.

32. Walker $\mathrm{DH}$. The role of host factors in the severity of spotted fever and typhus rickettsioses. Ann N Y Acad Sci. 1990;590:10-9.

33. Strid MA, Dalby T, Molbak K, Krogfelt KA. Kinetics of the human antibody response against Salmonella enterica Serovars Enteritidis and Typhimurium determined by lipopolysaccharide enzyme-linked immunosorbent assay. Clin Vaccine Immunol. 2007;14(6):741-7.

34. Pulickal AS, Gautam S, Clutterbuck EA, Thorson S, Basynat B, Adhikari N, et al. Kinetics of the natural, humoral immune response to Salmonella enterica serovar Typhi in Kathmandu, Nepal. Clin Vaccine Immunol. 2009;16(10):1413-9.

35. Blacksell SD, Smythe L, Phetsouvanh R, Dohnt M, Hartskeerl R, Symonds M, et al. Limited diagnostic capacities of two commercial assays for the 
detection of Leptospira immunoglobulin $\mathrm{M}$ antibodies in Laos. Clin Vaccine Immunol. 2006;13(10):1166-9.

36. Tsioutis C, Zafeiri M, Avramopoulos A, Prousali E, Miligkos M, Karageorgos SA. Clinical and laboratory characteristics, epidemiology, and outcomes of murine typhus: a systematic review. Acta Trop. 2017;166:16-24.

37. Center for Disease Control and Prevantion. Diagnosis and management of tickborne rickettsial diseases: rocky mountain spotted fever, ehrlichioses, and anaplasmosis. United States: A Practical Guide for Physicians and Other Health-Care and Public Health Profesionals: CDC; 2006.

38. Biggs HM, Behravesh CB, Bradley KK, Dahlgren FS, Drexler NA, Dumler JS, et al. Diagnosis and management of tickborne rickettsial diseases: rocky mountain spotted fever and other spotted fever group rickettsioses, ehrlichioses, and anaplasmosis - United States. MMWR Recomm Rep. 2016; 65(2):1-44.

39. Paris DH, Dumler JS. State of the art of diagnosis of rickettsial diseases: the use of blood specimens for diagnosis of scrub typhus, spotted fever group rickettsiosis, and murine typhus. Curr Opin Infect Dis. 2016;29(5):433-9.

40. Lokida D, Sudarmono P, Kosasih H, Butar-Butar DP, Salim G, Antonjaya U, Sari RA, Aman AT, Parwati I, Arif M, Lau CY, Karyana M. Comparison of commercial enzyme-linked immunosorbent assay and immunofluorescence assay for diagnosis of acute Rickettsia typhi infections. Vector Borne Zoonotic Dis. 2020:20(2):93-9.

\section{Publisher's Note}

Springer Nature remains neutral with regard to jurisdictional claims in published maps and institutional affiliations.

Ready to submit your research? Choose BMC and benefit from:

- fast, convenient online submission

- thorough peer review by experienced researchers in your field

- rapid publication on acceptance

- support for research data, including large and complex data types

- gold Open Access which fosters wider collaboration and increased citations

- maximum visibility for your research: over $100 \mathrm{M}$ website views per year

At $\mathrm{BMC}$, research is always in progress.

Learn more biomedcentral.com/submissions 